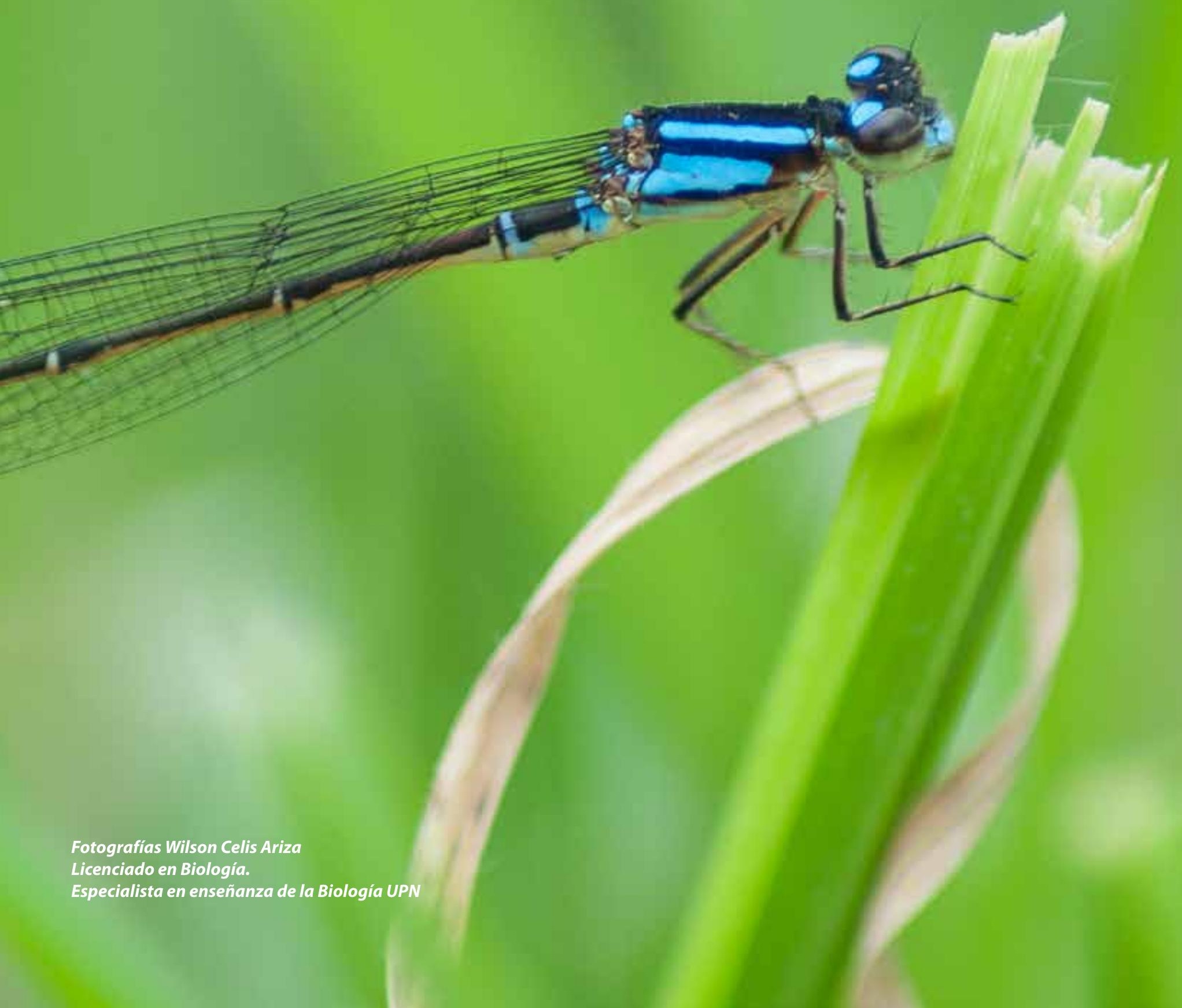




\section{DESCRITORES DAS ABORDAGENS DE ENERGIA EM LIVROS DIDÁTICOS BRASILEIROS DE BIOLOGIA DO ENSINO MÉDIO}

\section{Descriptors of energy approach in brazilian textbooks used on highschool's biology classeroom}

\section{Descritores de los plantamientos de energía en libros didácticos brasileños de Biología en la enseñanza secundaria}

Fecha de recepción: 18 de agosto de 2014

Fecha de aprobación: 2 de diciembre de 2014

\author{
Sandra Maria Wirzbicki \\ Maria Cristina Pansera de Araújo ${ }^{1}$ \\ José Claudio Del Pino
}

\section{Resumo}

O Programa Nacional do Livro Didático (PNLD, BRASIL, 2011) avalia e disponibiliza livros didáticos (LD) adequados aos estudantes da Educação Básica brasileira. Apesar disto, eles ainda apresentam deficiências, limitações e abordagens conceituais inadequadas com implicações no processo de ensino e aprendizagem em salas de aula. Objetivou-se identificar e analisar abordagens de 'energia' no metabolismo energético da biologia celular dos LD de Biologia do Ensino Médio (LDBEM), visando contribuir com o seu ensino. Para tanto, realizou-se análise documental do conceito 'energia' em LDBEM, quanto a sua adequação ao ensino e aprendizagem da respiração e metabolismo energético. Para tanto, considerou-se as possibilidades de entendimentos das abordagens do tema nos LDBEM, carentes de mediações específicas. A compreensão de 'energia' não é simples nem consensual. As descrições relativas ao metabolismo energético celular, em 8 coleções de LDBEM do Guia do PNLD/2012 (BRASIL, 2011), para a $1^{\text {a }}$ série foram analisadas e fundamentadas em Moraes e Galiazzi (2007). Procedeu-se a transcrição de excertos dos LDBEM, ao conceituar 'energia' e suas relações com o metabolismo. Foi possível reconhecer cinco categorias de descritores do conceito 'energia': 1) Seres vivos e energia na respiração, fermentação e fotossíntese; 2) Energia nas substâncias, nas ligações químicas e nas reações dos organismos - ADP e ATP; 3) Tipos e fontes de energia; 4) Energia na área de CNT; 5) Representações de energia (figuras, modelos, tabelas,...). Muitas vezes, estas explicitações estão distantes do ensino ou de reflexões sobre a significação conceitual, tanto na educação básica quanto na formação docente, constituindo obstáculos a aprendizagem.

\section{Palavras-chave}

Energia, livros didáticos; ensino de Biologia

\section{Abstract}

National Program of Texbooks (PNLD- Brazil) evalue and spread the appropriate textbooks (TB) for students of Brazilian Basic Education. Despite this, they still have shortcomings, limitations and inadequate conceptual approaches with implications for teaching and learning in classrooms. Aimed to identify and analyze the 'energy' approaches in the energy metabolism of cell biology in Biology TB at Highschool (BTBHS), in order to contribute to their education. In this sense, a documentary analysis

1 Professora titular Grupo Interdepartamental de Pesquisa em Educação em Ciências - Gipec-Unijui. Dep. de Biologia e Química - Unijui São Francisco 501, São Geraldo CEP98700-000 ljui, RS. Correo electrónico: pansera95@gmail.com 
of the 'energy' concept was carried out by TBHS, in regards to its adequacy for the teaching and learning of respiration and energy metabolism. We considered the contribution to the understanding of the TBHS theme's approaches, still lacking specific mediations. The 'energy's understanding is neither simple nor consensual', and the descriptions related to cellular energy metabolism were observed in 1th textbook from 8 colections of TBHS recomended by PNLD/2012 Guide (Brasil, 2011). Based on Moraes \& Galiazzi (2007), the transcript of TBHS excerpts was undertaken and then the 'energy's way and its relationship to metabolism was analysed. It was possible to recognize five descriptors's categories: 1) Living beings and energy in respiration, fermentation and photosynthesis; 2) Energy in substances, chemical bonds and reactions of organisms - ADP and ATP; 3) Types and sources of energy; 4) Energy in the Natural Sciences area; 5) Energy representations (Figures, templates, tables,...). These clarifications are distant of teaching itself or the reflections about the conceptual significance, at both education levels, basic or higher, constituting often obstacles to learning.

\section{Key-words}

Energy, books of didatics; Biology classes

\section{Resumen}

El Programa Nacional del Libro Didáctico (PNLD- Brasil) evalúa y dispone libros didácticos (LD) adecuados a los estudiantes de la Educación Básica Brasileña. A pesar de esto, todavía presentan deficiencias, limitaciones y planteamientos conceptuales inapropiadas con implicaciones en el proceso de enseñanza y aprendizaje. El objetivo fue identificar y analizar el abordaje de la 'energía' en el metabolismo energético de la biología celular en los LD de Biología en la Enseñanza Secundaria (LDBES). Por lo tanto, se ha realizado un análisis documental del concepto de 'energía' en LDBES, en cuanto su adecuación a la enseñanza y aprendizaje de la respiración y metabolismo energético. Esta investigación considera las posibilidades de comprensión de los enfoques de los LDBES, carente de mediaciones específicas. La comprensión de la 'energía' no es simple ni consensual, por eso fueron observadas las descripciones relativas al metabolismo energético celular, en el libro del $1^{\circ}$ grado de 8 colecciones de LDBES del Guía del PNLD/2012 (Brasil, 2011). Basado en Moraes \& Galiazzi (2007), se hicieron las transcripciones de extractos de los LDBES analizados, sobre el tema. Fue posible reconocer cinco categorías de descriptores del concepto de energía: 1) Seres vivos y energía en la respiración, fermentación y fotosíntesis; 2) Energía en las sustancias, enlaces químicosy reacciones de los organismos-ADP eATP;3) Tipos y fuentes de energía; 4) Energía en el área de CNT; 5) Representaciones de energía (figuras, modelos, tablas,...). Muchas veces, estas explicaciones están distantes de la enseñanza o de las reflexiones sobre el significado conceptual, tanto en la enseñanza básica como en la formación docente, constituyendo obstáculos para el aprendizaje.

\section{Palabras-clave}

Energia, libros didácticos; enseñanza de Biologia

\section{Introdução}

Pesquisar livro didático (LD) no Brasil não é recente, até recorrente, desde a década de 70 quanto a qualidade das coleções didáticas, deficiências e soluções para melhorar a sua organização, abordagem conceitual científica e humanística, dentre outros aspectos. O LD constitui tema de diversos grupos de pesquisa do Brasil entre os quais o do projeto: "A linguagem e a literatura na educação em ciências: as relações e entendimentos dos professores universitários", vinculado ao Programa de Pós-Graduação em Educação nas Ciências - Química da Vida e Saúde da Universidade Federal do Rio Grande do Sul (PPGQVS-UFRGS) e o Grupo Interdepartamental de Pesquisa sobre Educação em Ciências da Universidade Regional do Noroeste do Estado do Rio Grande do Sul (Gipec-Unijuí), em que esta pesquisa vem sendo desenvolvida, como parte da tese de doutorado.

Algumas referências importantes sobre a questão são Pretto (1985); Mortimer (1988); Fracalanza (1993); Pimentel (1998), Silva (2000); Carvalho et al (2003); Selles e Ferreira (2004), Güllich (2004/2012); Megid Neto (2006); Amaral (2006); Martins (2006); Lopes (2007); Emmel, Gullich, Pansera-de-Araújo (2009), Emmel (2011), Occelli, Valeiras (2013). Todas estas pesquisas tem repercutido pouco nas editoras, que publicam os livros didáticos.

Estas pesquisas permitem pensar na superação de algumas questões apontadas quanto ao uso do LD na área e suas interfaces com o ensino, sejam elas: a crítica ao livro e a crítica à crítica ao mesmo. Emmel et al (2012) ainda propõem outra questão: o que fazer com os LD, que continuam chegando as escolas, como política de estado (AMARAL, 2006; CARVALHO; GIL-PÉREZ, 2000). 
Mesmo com várias possibilidades de abordar conteúdos, em processos de ensino de Ciências da Natureza e suas Tecnologias (CNT), o LD, ainda, constitui o principal recurso didático entre os poucos utilizados no planejamento e desenvolvimento das aulas. Por isso, é fundamental empreender esforços no sentido de uma compreensão mais ampla das repercussões, no ensino, de formas diferenciadas de tratamento dos conteúdos nos LD. Nesta área, abordagens convencionais refletem a visão de uma sequência linear e fragmentada de conteúdos, o que tende a dificultar o desenvolvimento de conceitos escolares, que contemple inter-relações de conhecimentos diversificados.

Com o Programa Nacional do Livro Didático (PNLD), os LD tornaram-se um recurso disponível para todos os estudantes da Educação Básica brasileira. A própria análise deste material alerta para suas limitações, ao referir que a maioria das imagens associadas aos conhecimentos biológicos:

\section{[...] são apenas ilustrativas de conteúdos. São imagens que [...] apresentam o organismo humano e demais seres vivos de modo fragmentado. Os livros didáticos aqui resenhados, em regra geral, ainda dialogam pouco com a condição marcante do tempo atual (BRASIL, 2011, p.20).}

Possivelmente, os LD assumem tais características, pela visão positivista, "em que as ciências exatas e naturais reafirmam as crenças em si mesmas e se fecham em suas exclusivas competências, segundo uma lógica desvinculada dos fins humanos" (MARQUES, 1988, p.66-87).

Atualmente, nas diversas áreas do conhecimento, as atenções têm sido direcionadas para a construção de uma escola que eduque para a vida mediante conhecimentos e práticas associadas ao desenvolvimento de capacidades, competências, valores e atitudes. Nesse cenário, para ensinar CNT, é fundamental enfrentar e lidar com constantes desafios, bem como repensar e superar as práticas tradicionais de ensino dos conteúdos científicos escolares, que ainda subsistem, em que pese amplas possibilidades de mudança propostas pelas Orientações Curriculares Nacionais para o Ensino Médio (OCNEM, BRASIL, 2006), na perspectiva de promover um ensino mais significativo, que contemple expectativas de desenvolvimento mental e cognitivo dos estudantes.

Em decorrência da promulgação da Lei de Diretrizes e Bases da Educação Nacional (LDBEN-Brasil) movimentos de mudança no currículo, no ensino e na formação de professores passaram a ser objeto de estudos e discussões, em diferentes níveis educativos e campos de saber.
O desafio de concretizar um ensino para potencializar o pleno desenvolvimento do educando (Art. $1^{\circ}$; BRASIL, 1996) contrapõe-se aos aprendizados de Ciências marcados pela tendência a uma mera repetição de respostas prontas, 'com as mesmas palavras'. Ainda, permanece a relação dicotômica entre as práticas escolares e os discursos prescritivos de especialistas ou das políticas públicas.

Dificuldades associadas ao movimento de reforma da educação dizem respeito à própria complexidade da compreensão do que seja um ensino de Ciências, que assegure o pleno desenvolvimento dos estudantes. Nesta pesquisa, partindo-se do entendimento de que a aprendizagem propicia os processos de desenvolvimento humano (VIGOTSKI, 2001), discutem-se fatores condicionantes dos aprendizados no ensino das Ciências. Assumindo que o significado de um conceito está sempre associado com movimentos de relação em redes complexas de conexão, direcionamos o olhar para condições de ensino, que na maioria das situações resulta em aprendizados isoladose repetitivos, que pouco ou nada contribuem para o pleno desenvolvimento das potencialidades humanas.

Em estudo anterior, Wirzbicki (2010), já discutiu, numa perspectiva histórica, que o ensino de Ciências passou e continua passando por alterações, apresentando, ainda hoje insuficiências e dificuldades no âmbito escolar. Por isso, é importante empreender discussões e reflexões que proponham melhorias; visto que o ensino de CNT, ainda hoje,

Infelizmente, mantém-se [...] precário com professores que enfrentam nas escolas problemas de sobrecarga, de falta de recursos e de determinações que deveriam seguir sobre as quais não foram ouvidos. As modificações promovidas por diferentes elementos ao longo dos diversos patamares de decisões que atuam nos componentes curriculares - temáticas e conteúdo, modalidades didáticas, recursos e processos de avaliação - confluem para um cenário que raramente é o planejado pelos emissores do currículo teórico. (KRASILCHIK, 2000, p. 88)

Neste trabalho, o olhar volta-se aos enfoques de 'energia' em LD de biologia para o Ensino Médio (LDBEM), relativas à biologia celular e ao metabolismo energético, no que se refere a preocupações e possíveis decorrências no Ensino Médio (EM), em CNT, particularmente, quanto à adequação dos tratamentos didáticos para a significação conceitual. $\mathrm{Na}$ Ciência, o entendimento do que é a 'energia' não pode ser visto como uma concepção simples nem consensual, sendo importante considerar as amplitudes dos significados, a exemplo da explicação expressa por Angotti (1991) e corroboradas por Auth (2000) de que a 'energia' é: 
um "sutil camaleão" do conhecimento científico. Transforma-se espacial e temporalmente, na dinâmica mutável dos objetos, fenômenos e sistemas, conserva-se na totalização das distintas formas e degrada-se porque uma de suas formas - o calor - é menos elástico e reversível do que outras (p.115 AUTH, 2000, p. 7).

$\mathrm{Na}$ área das CNT, conceitos, como é o caso de 'energia, são tratados de forma diferenciada na Biologia, Física e Química (PANSERA-DE-ARAÚJO; NONENMACHER, 2009), e no caso de abordagens transdisciplinares, tampouco contemplam inter-relações de conhecimentos entre disciplinas (WIRZBICKI; ZANON, 2009). Isto situa e justifica os estudos em busca de conhecimentos e ações, que contribuam para a perspectiva de articulação dos conceitos/conteúdos na área, tanto na formação inicial quanto continuada de professores.

Como exemplo, no EM percebe-se uma ampliação crescente de abordagens e explicações sobre a biologia e a respiração celular, sendo preocupante a constatação de que, em LDBEM, elas abrangem crescentes tratamentos de conteúdos bioquímicos, cuja compreensão envolve graus elevados de abstração e requerem o domínio de áreas conceituais como a Química, a Física e a Biologia. As abordagens do referido conteúdo (direcionadas para a $1^{\text {a }}$ série do EM) incluem estudos e entendimentos sobre composição química da célula, as vias metabólicas e suas relações com processos de produção e consumo de Adenosina tri-fosfatada (ATP), forma de 'energia' que mantém os processos vitais. A respiração é um tema vivenciado pelos estudantes quando se refere a sensação de "falta de ar" experienciada, em situações específicas. No entanto, sob o ponto de vista biológico outros aspectos do funcionamento dos organismos são englobados na respiração celular e metabolismo energético.

A análise das abordagens conceituais relacionadas a este tema mostra que em contexto escolar, trata-se de um conteúdo do ensino de CNT bastante complexo, cujos estudos requerem compreensões com graus elevados de abstração, como as relativas à atuação de enzimas no metabolismo celular. Esta problemática carece de atenção em contextos de planejamento e execução das práticas curriculares em CNT, no EM, contrapondo-se a visões limitadas e fragmentadas, da área, presentes na maioria dos LDBEM que tratam 'energia', a partir de ideias como "libera energia", usualmente utilizadas em situações cotidianas. Estudos realizados por Oliveira e Santos (1998), Mortimer e Amaral (1998) e Barros (2009) referendam a necessidade de mediar explicações sobre energias envolvidas: compreensões de energia interna, conservação e transformação da matéria e energia, interconversões de energia no âmbito de estudos de calor, energia química, termoquímica entre outros.

Este estudo do conceito de 'energia' considera a potencialidade de contribuir no avanço de entendimentos sobre o referido conceito nos LDBEM, carentes de mediações de linguagens específicas que, muitas vezes, não fazem parte do ensino aos estudantes ou de reflexões desenvolvidas junto à formação docente. A relevância do trabalho justifica-se também pela amplitude das relações deste conceito com outros da área de CNT, com inúmeras possibilidades de produção de sentidos aos significados conceituais relativos a abordagens de diferentes temas em estudo, a exemplo de processos metabólicos vitais como a respiração.

A questão de pesquisa é: que abordagens de 'energia' nos LDBEM propiciam ou limitam relações para reconstrução de significados e contribuem com o processo de ensino e aprendizagem escolar em CNT?

\section{Materiais e Método}

A metodologia proposta para o desenvolvimento deste trabalho enfoca uma pesquisa de natureza qualitativa, com análise documental que, segundo Lüdke e André (1986), caracteriza-se pela coleta de dados. Neste caso, os documentos são os LDBEM utilizados por professorese estudantes do EM das escolas públicas estaduais e municipais de ljuí/Rio Grande do Sul, Brasil.

Com base nestes entendimentos, as descrições relativas ao metabolismo energético celular foram observadas e analisadas nos livros da $1^{\text {a }}$ série do EM de 8 coleções de LDBEM do Guia do PNLD/2012 (Brasil, 2011), constituindo o Corpus da pesquisa. Estes livros de Biologia foram identificados como LDBEM1, LDBEM2, LDBEM3 e assim sucessivamente, até a $8^{\text {a }}$ coleção. Somente na $6^{\text {a }}$ coleção, foram analisados os volume 1 e 3 , já que os dois apresentam aspectos do metabolismo energético, assim, o LDBEM6 ficou identificado por LDBEM6.1 e LDBEM 6.3, respectivamente.

A análise identificou recortes de imagens explicativas das transformações de 'energia', que requerem compreensões específicas acerca de conteúdos/conceitos diversificados, como: célula, mitocôndria, metabolismo, reação enzimática, ATP, energia.

Além disso, a partir de Moraes e Galiazzi (2007), procedeu-se a transcrição e unitarização de excertos dos LDBEM analisados, ao conceituar 'energia' e suas relações com o metabolismo, sistematizados em tabelas. Foi possível 
reconhecer um conjunto de descritores, identificados por palavras e agrupados em cinco categorias.

\section{Resultados e Discussão: As abordagens de 'energia' nos LDBEM}

Mesmo com abordagem variada dos conteúdos de CNT, o LD constitui o principal recurso em sala de aula. É fundamental empreender esforços para compreender as repercussões, no ensino, do tratamento dos conteúdos nos LD, que, ainda, reforçam a visão linear e fragmentada. O entendimento de 'energia' não é algo simples nem consensual, por isso observaram-se as descrições relativas ao metabolismo energético celular, nos LDBEM do Guia do PNLD/2012 (Brasil, 2011), para a $1^{\text {a }}$ série.

Os descritores identificados por palavras, agrupados em cinco categorias são: 1) Seres vivos e energia na respiração, fermentação e fotossíntese; 2) Energia nas substâncias, nas ligações químicas e nas reações dos organismos - Adenosina di-fosfatada (ADP) e ATP; 3) Tipos e fontes de energia; 4) Energia na área de CNT; 5) Representações de energia. A análise resultou na transcrição de 289 excertos, dos quais 128 na categoria $1 ; 121$ excertos na $2 ; 10$ excertos na 3; 12 excertos na 4; e, 18 excertos na 5 (Tabela 1).

Pela complexidade dos resultados obtidos, neste artigo, analisaremos excertos referentes as categorias 1,2 e 5 . No conjunto de descritores das categorias 1 e 2, percebeu-se um número significativo de sinônimos, o que pode ser um problema para a aprendizagem. Este problema pode referir-se a riqueza de palavras/sinônimos da língua portuguesa ou, a um conjunto de palavras vazias, que podem impedir o desenvolvimento cognitivo e a evolução da compreensão conceitual. Ao reconhecer esta questão, as razões do 'fracasso' do desempenho escolar de estudantes tem seu foco deslocado, visto que professores desatentos à perspectiva histórico-cultural se enganam ao pensar que o estudante está entendendo suas intervenções, muitas vezes limitadas aos LD. Frequentemente, identifica-se ausência de relações com outros conhecimentos produzidos nos contextos cotidianos dos sujeitos envolvidos. Por exemplo, no caso do complexo conceito 'energia', ainda que os estudantes usem signos típicos ao contexto escolar, como as expressões 'captada', 'armazenada', 'transformada', 'energia de ativação', isso não significa que os mesmos, necessariamente, tenham produzido sentidos e significados escolares, de forma adequada. Conforme Vigotski (2001):

Não menos que a investigação teórica, a experiência pedagógica nos ensina que o ensino direto de conceitos sempre se mostra impossível e pedagogicamente estéril. O professor que envereda por esse caminho costuma não conseguir senão uma assimilação vazia de palavras, um verbalismo puro e simples que estimula e imita a existência dos respectivos conceitos na criança, mas, na prática, esconde o vazio. Em tais casos, a criança não assimila o conceito, mas a palavra, capta mais de memória que de pensamento e sente-se impotente diante de qualquer tentativa de emprego consciente do conhecimento assimilado. No fundo, esse método de ensino de conceitos é a falha principal do rejeitado método puramente escolástico de ensino, que substitui a apreensão do conhecimento vivo pela apreensão de esquemas verbais mortos e vazios. (p. 247)

Portanto, a utilização de diferentes palavras referentes a um mesmo fenômeno biológico, pode constituir dificuldades de entendimento dos estudantes tanto na leitura dos textos didáticos, quanto na exposição do professor. Nesse sentido, cabe aos professores constituir situações de aprendizagem, que permitam aos estudantes usarem palavras (signos, linguagens, simbologias, representações) adequadas à expressão do pensamento típico à forma escolar de conhecer. Os processos de formação de conceitos resultam das interações com outros, então, interferir intencionalmente na aprendizagem é de grande importância para que os sujeitos envolvidos possam aprender.

No caso dos estudantes do EM, exige-se uma boa compreensão de conceitos abstratos, que se formam a partir da adolescência, porém, a capacidade de assimilição por parte dos estudantes, em geral, não são consideradas. Para muitos professores ensinar os conceitos é algo mecânico, sem refletir sobre os níveis de abstração necessários à compreensão dos adolescentes.

A complexidade e os graus de dificuldade dos estudos sobre 'respiração celular' residem na necessidade de uso, por parte dos estudantes, de conceitos básicos de Química e de Biologia, abstratos por sua natureza, bem como da capacidade de entendê-los de forma dinamicamente inter-relacionada. 


\begin{tabular}{l|l|l|}
\multicolumn{1}{|c|}{ Categorias dos descritores } & \multicolumn{1}{c|}{ Conjunto de Descritores } & $\begin{array}{c}\text { Número de } \\
\text { Excertos }\end{array}$ \\
$\begin{array}{l}\text { 1) Seres vivos e energia na respiração, fermentação e } \\
\text { fotossíntese; }\end{array}$ & $\begin{array}{l}\text { Liberar, obter, produzir, captar, absorver, transportar, } \\
\text { provir e fornecer; }\end{array}$ & 128 \\
\hline $\begin{array}{l}\text { 2) Energia nas substâncias, nas ligações químicas e nas } \\
\text { reações dos organismos - ADP e ATP; }\end{array}$ & $\begin{array}{l}\text { Armazenar, acumular, reservar, conter, transferir, trans- } \\
\text { formar, converter e ATP/ADP; }\end{array}$ & 121 \\
\hline $\begin{array}{l}\text { 3) Tipos e fontes de energia; } \\
\text { 4) Energia na área de CNT; }\end{array}$ & Energia solar, energia cinética, potencial,...; & 10 \\
\hline $\begin{array}{l}\text { 5) Representações de energia (figuras, modelos, tabe- } \\
\text { las,...). }\end{array}$ & Representações. & 12 \\
\hline
\end{tabular}

Tabela 1: Categorias de Abordagem do conceito 'energia' nos LDBEM analisados

Na identificação dos descritores das categorias 1 e 2, reconhecemos problemas na organização conceitual o que constituiu três subcategorias: i) utilização de diferentes palavras para um mesmo aspecto; ii) analogias para explicar reações submicroscópicas e, iii) complexidade na expressão conceitual. As categorias são exemplificadas, no Quadro 1, com excertos de LDBEM analisados nesta pesquisa

Os descritores acerca do tema 'energia', citados na subcategoria i)constituem-se em explicações e/ou teorizações diferenciadas, que precisam ser recolocadas e ampliadas. São noções que abrangem uma complexidade de entendimentos, nem sempre confirmadas como inerentes ao ensino de CNT, que podem ser remetidas a especificidades de sentidos e significados conceituais produzidos, validados e usados no âmbito de cada uma das comunidades científicas da área. Assim, uma diversidade de entendimentos relativos ao conceito 'energia' como aquelas referidas por Moreira (1998), complexifica a compreensão conceitual do mesmo, em sentido mais amplo:

Existem três formas básicas de energia: a cinética, devido ao estado de movimento de um corpo; a potencial, devida ao efeito de forças exercidas sobre um corpo por outros corpos; e a energia de massa (a equação de Einstein, $E=m c 2$, estabelece uma equivalência entre massa e energia). É claro que essa classificação é muito geral e em muitos casos é conveniente falar em "outras formas" de energia como energia elástica, energia elétrica, energia química, energia eólica, energia nuclear, mas, no fundo, todas essas outras formas estão incluídas nas três formas básicas. (MOREIRA, 1998, p. 2)
Sem desconsiderar a importância e, ao mesmo tempo, a complexidade do conceito 'energia' é importante considerar, com apoio em Vigotski (2001), a visão de que é na adolescência, sobretudo com a escolarização, que é possibilitado o pleno desenvolvimento das capacidades superiores do ser humano, constituindo-se a escola numa condição essencial a tal desenvolvimento. Para isto, é essencial o acesso do adolescente a outras formas de linguagem e pensamento, mediante $o$ acesso a signos e significados próprios aos conhecimentos escolares, que incluem relações entre sentidos atribuídos aos conceitos, em contextos socioculturais diversificados, incluindo relações com os significados típicos a cada Ciência que se ensina e se aprende nas salas de aula. 


\section{i) Utilização de diferentes palavras para um mesmo aspecto}

\section{Excertos identificados nos LDBEM analisados}

Excerto 1 - LDBEM 8 p. 124- "Esse processo (degradação e perda de energia por meio de calor) é possível graças a um mecanismo conhecido como acoplamento de reações, em que algumas substâncias armazenam temporariamente a energia que será posteriormente transferida, de modo que a perda sob a forma de calor seja a menor possível. Uma dessas substâncias é o trifosfato de adenosina ou adenosina trifosfato (ATP)"; (Grifos nossos)

Excerto 2 - LDBEM 6.1 p. 262 - "Energia química: a energia "escondida" Os átomos de uma molécula estão ligados entre si por determinadas forças. Podemos considerar, assim, que nas moléculas existe energia "escondida" ou armazenada, chamada de energia de ligação ou energia química. Quando, numa reação química, uma molécula se transforma em outra, parte dessa energia pode ficar disponível e se transformar em qualquer outro tipo de energia." (Grifos nossos)

Excerto 3 - LDBEM 6.3 p. 20 - "Lembre-se de a energia liberada pela respiração celular ou pela fermentação nunca é usada diretamente no trabalho celular. Ela é inicialmente armazenada em uma molécula especial, o ATP (adenosina trifosfato ou trifosfato de adenosina), sob a forma de ligações químicas muito ricas em energia." (Grifos nossos)

Quadro 1: Exemplos de excertos da organização conceitual com utilização de diferentes palavras para um mesmo aspecto

O uso de analogias foi identificado em cinco dos nove LDBEM investigados (Quadro 2). Se o professor não tiver uma leitura crítica ou interferir nestas abordagens, elas podem prejudicar a aprendizagem de conceitos, confundindo o estudante. Conforme Lopes (1996), a aprendizagem é dificultada ainda mais pelo uso de metáforas e analogias, com o intuito de efetuar o ensino do conhecimento científico ao estudante, em detrimento do conteúdo e da conceitualizaçãoalmejada. Esta última constitui uma questão importante no desenvolvimento cognitivo e das funções mentais superiores (VIGOTSKI, 2001).

Como já discutido neste trabalho, é importante que, no ensino de CNT, os aprendizados dos conteúdos/conceitos extrapolem os conhecimentos restritos à uma única disciplina ou a um método, ou a um recurso. É importante ter uma visão crítica sobre o ensino, seja nas abordagens em LD ou em aulas, em que as explicações limitam-se à introdução de analogias e metáforas que, ao invés de propiciar avanços nas compreensões conceituais, permanecem nas formas familiares de conhecimento, típicas ao conhecimento cotidiano, constituindo obstáculos à construção dos conhecimentos escolares. Essa linha de reflexão traz à tona considerações sobre os obstáculos epistemológicos bachelardianos:

Não podemos, contudo, considerar que Bachelard defende a impossibilidade de utilização de metáforas e imagens. Sua posição é de que a razão não se pode acomodar a elas, devendo estar pronta a desconstruí- -las sempre que o processo de construção do conhecimento científico assim o exigir (BACHELARD, 1970: 63). Há mesmo em sua obra (BACHELARD, s.d: 84-85) uma discussão a respeito das boas e das más imagens, úteis para descrever um mundo que não se vê, devem ser empregadas em instância de redução: redução a ser feita pela matematização. Temos que entender as imagens como uma instituição de meios matemáticos de compreensão racional das leis e não como uma afirmação dogmática da realidade (LOPES, 1996, p. 263). 


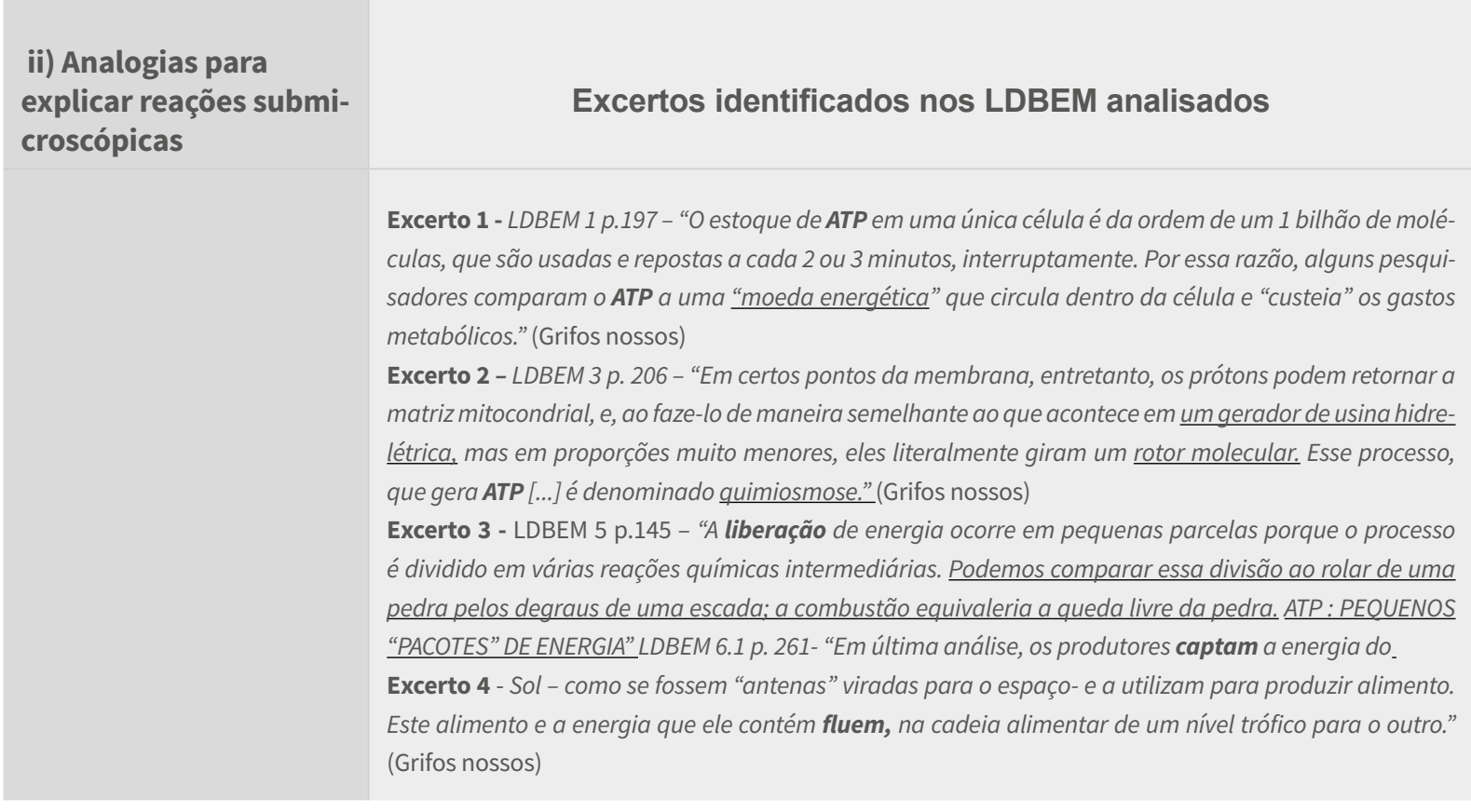

Quadro 2: Exemplos de excertos da organização conceitual com analogias para explicar reações submicroscópicas

Já no quadro 3, observa-se nos excertos apresentados a complexidade dos conceitos básicos de Biologia e Química, abstratos por natureza, que necessitam ser usados, com mobilização da capacidade de pensar conceitualmente sobre eles, de forma dinamicamente inter-relacionada. Trata-se de conceitos, cujos significados assumem vieses diferenciados no âmbito cultural próprio a cada uma das disciplinas da área de CNT.

\section{iii) Complexidade na expressão con- ceitual}

\section{Excertos identificados nos LDBEM analisados}

Excerto 1 - LDBEM 8 p. 321 - Sabemos que o Sol é a fonte direta e indireta de energia para a maioria das formas de vida do planeta. A partir da energia solar, seres clorofilados, como as plantas, realizam fotossíntese e são a base de muitas cadeias alimentares. Plantas também realizam a respiração celular do mesmo modo que os animais e, assim como eles, respiram tanto de dia quanto de noite. É nas células dos seres vivos que se dá o metabolismo energético. (Grifos nossos)

Excerto 2 - LDBEM 2 p.125 - "Devido as forças de atração molecular, os átomos de fósforo ligam-se mais fortemente quando próximos da ribose, e mais fracamente quando distantes. Assim, o fosfato que fica na extremidade da molécula tende a liberar-se mais facilmente, liberando também a energia de ligação (reação exotérmica). Essa energia é imediatamente utilizada em alguma outra reação endotérmica."

Excerto 3 - LDBEM 3 p.200 - "Estudaremos a seguir como a célula consegue, canalizando elétrons para as mitocôndrias, e com consumo de oxigênio, realizar essa reação química de maneira lenta em várias etapas, com produção de água e liberação gradual de energia, que é utilizada para fabricar moléculas de ATP.”

Excerto 4 - LDBEM 7 p.64 - Fermentação alcoólica Para poder reagir, cada molécula de glicose consome inicialmente 2 ATP para ser ativada. Quando isso ocorre, a molécula de glicose começa a sofrer várias reações até originar duas moléculas de ácido pirúvico. No decorrer dessas reações, há liberação de energia suficiente para recompor 4 ATP. Cada molécula de ácido pirúvico, em seguida, sofre uma descarboxilação e se transforma em álcool etílico ou etanol. Saldo energético na fermentação alcoólica:

4 ATP produzidos -2 ATP consumidos para ativar a glicose $=2$ ATP.

Quadro 3: Exemplos de excertos da organização conceitual com complexidade na expressão conceitual 
Nestes excertos podemos reconhecer as limitações na conceitualização da 'energia' nos seres vivos, o que pode complicar a aprendizagem e constituição do conhecimento científico pelos sujeitos, já que ainda impõe uma visão linear e descontextualizada. A complexidade na expressão conceitual, vinculada a um grau de abstração elevado, constitui-se outra dificuldade. Ao reconhecer o conjunto de descritores, abre-se uma perspectiva de reflexão sobre a organização do currículo escolar ainda alinhado exclusivamente ao proposto pelos livros didáticos. Nesse sentido, Silva (2000) afirma que:

[...] novos estudos sobre as práticas pedagógicas e as políticas educacionais ligadas aos livros didáticos precisam situar-se no mundo real da clientela da escola pública tendo em vista a necessidade de idéias que possam resultar na efetiva adequação da escola à realidade social e às necessidades cognoscentes dos alunos de classes populares. (p. 31)

As compreensões, que extrapolam os conhecimentos usuais de um professor de Biologia, requerem conceitos químicos que, isolados e descontextualizados, não bastam por si só. Por exemplo, cabe ao professor de Química contribuir com as explicações relativas às substâncias, transformações e interações em nível atômico-molecular. Será que o professor de Biologia do EM tem conhecimento de tal complexidade, ou repete as informações dos LD de forma a ser memorizada?

\section{Um olhar para as imagens dos livros didáticos}

Temos percebido aumento significativo de figuras sobre a respiração celular nos LDBEM orientadas ao ensino da $1^{a}$ Série do EM, quando os estudantes recém tiveram acesso aos primeiros conhecimentos de Química, como área. Nesta pesquisa foram descritas 18 situações que se referem a representações e tabelas, figuras e imagens, que constituíram a categoria 5, aqui analisada. Observam-se figuras e abordagens escritas, que representam objetos complexos, com graus elevados de abstração, associadas a compreensão adequada sobre transformações químicas, que mantém a vida.

Nesta série, nem sempre é possível uma compreensão adequada de tais objetos representados nas figuras em LDBEM, pela insuficiência de conhecimentos químicos necessários ao entendimento das próprias estruturas moleculares e supramoleculares envolvidas, bem como pela pouca capacidade de abstração dos estudantes. Nesta linha de compreensão, Vigotski refere que:
[...] estudos especiais mostram que só depois dos doze anos, ou com o início da puberdade e ao término da primeira idade escolar, começam a desenvolver-se na criança os processos que levam a formação dos conceitos e ao pensamento abstrato. Pode-se considerar que a criança atinge tarde o grau de socialização de seu pensamento, que é necessário para a elaboração de conceitos plenamente desenvolvidos. (2001, p.159)

Assim, aprendizados deturpados e limitados não propiciam processos de significação conceitual em nível atômico-molecular. Os estudantes não significam as palavras e pouco compreendem do objeto teórico representado pela imagem, que cria obstáculos à construção do conhecimento escolar. Essa linha de reflexão traz à tona considerações sobre os obstáculos epistemológicos bachelardianos, em que:

[...] o acúmulo de imagens prejudica evidentemente a razão, no qual o lado concreto, apresentado sem prudência, impede a visão abstrata e nítida dos problemas reais.

Quando a abstração se fizer a presente, será a hora de ilustrar os esquemas racionais. Em suma, a intuição primeira é um obstáculo para o pensamento científico; apenas a ilustração que opera depois do conceito, acrescentando um pouco de cor aos traços essenciais, pode ajudar o pensamento científico. (BACHELARD, p. 93/97, 2011)

Na Figura 1, o objeto refere-se às "reações acopladas" mediadas pelas interconversões ATP/ADP, que já foi evidenciado no excerto 1 do LDBEM 8, no Quadro 3. Ou seja, percebe-se que a questão das interconversões ATP/ADP é "maltratada" tanto no texto escrito quanto nas analogias usadas para provocar o entendimento do fenômeno em estudo.

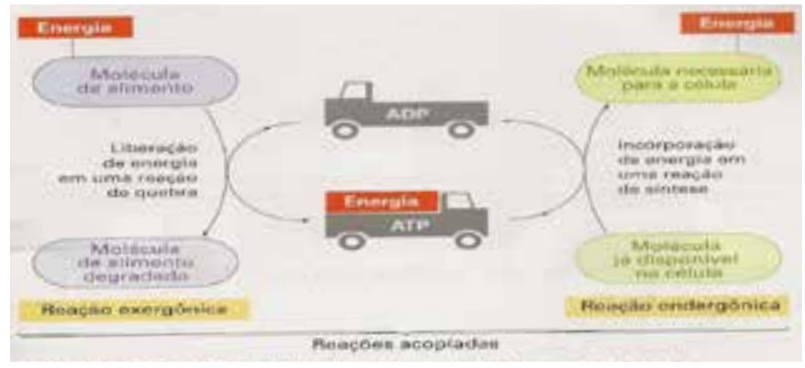

Figura 1 - Representação das "Reações Acopladas" Fonte: LDBEM 8 (p.323)

Legenda da figura no LDBEM: Esquema de duas reações acopladas nas quais o ATP funciona como substância comum, com a função de transportar energia. 
A imagem denota uma simplificação de noções complexas, não permitindo compreensão adequada sobre as interconversões de 'energia' envolvidas no complexo sistema de transformações, que propicia o acúmulo de 'energia' (ATP) na vida. O uso do termo 'liberação compromete a compreensão conceitual', pelo risco de uma visão mecanicista de 'energia'. Pode-se dizer que em representações como as desta figura, conceitos como os de reação 'exergônica' e 'endergônica' são tratados de forma simplista, sem considerar a complexidade dos processos de transformação e conservação de 'energia', envolvidos na compreensão do objeto em estudo. Sua interpretação requer o entendimento conceitual das transformações como sistemas complexos, como é o caso das interconversões energéticas associadas a compreensão conceitual da respiração celular, que requer movimentos dialéticos de 'ir e vir' entre os níveis macro e microscópicos de conhecimento.

A imagem de um mero movimento de caminhões num ir e vir, com ou sem a 'carga' cria um obstáculo ao desenvolvimento dos conhecimentos escolares sobre as transformações em nível submicroscópico, coerentes com a forma científica de explicação. Nos termos bachelardianos, é necessária uma vigilância epistemológica frente a imagens como esta, que acomodam o pensamento, obstacularizando os entendimentos conceituais necessários da mediação escolar.

A própria compreensão conceitual das Figuras 2 e 3 é problemática, por requerer novamente aprendizados de Química ainda não desenvolvidos na $1^{\text {a }}$ Série do EM, para entender estruturas moleculares como as da adenosina, do ATP, ADP e Adenosina mono-fosfato (AMP). Isto por sua vez, compromete a compreensão das interconversões ATP/ADP como ruptura/formação de ligações químicas:

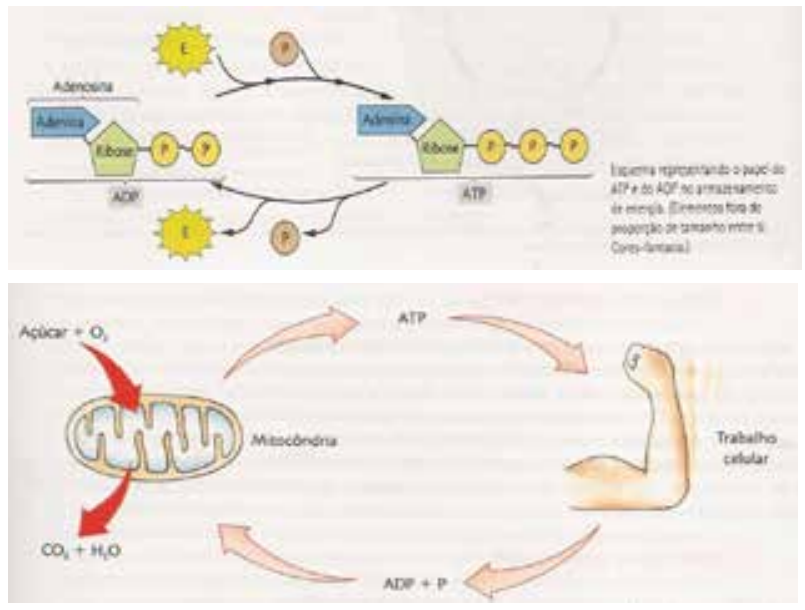

Figura 2 e 3 - Representação do "ATP: A Moeda Energética dos Seres Vivos" Fonte: LDBEM 6.3 (p. 20-21)
A noção representada nas Figuras 2 e 3, refere-se a compreensão de que a "interconversão ATP/ADP" faz parte do "ciclo do ATP/ADP". Abrange um sistema de relações entre conceitos, a começar pela concepção de respiração celular, trabalho, contração muscular, mitocôndria, nutriente energético, reação química endo/exoergônica, dentre outros. Explicações relativas aos sistemas de reações enzimáticas e vias metabólicas inter-relacionadas que transformam 'combustíveis' em gás carbônico e água, nas mitocôndrias, com consumo de oxigênio, requerem uma complexidade de conhecimentos sobre transformações em nível atômico molecular, com graus elevados de abstração, nem sempre possíveis no EM.

Nos níveis microscópicos ainda existem as dúvidas quanto à associação de ruptura e formação de ligações (ou de interações intermoleculares), como também quanto à identificação desses fenômenos com alterações na energia potencial das partículas envolvidas. (BARROS, 2009, p.1).

Dificuldades de compreensão conceitual de processos de transformação de estruturas moleculares são preocupantes, considerando-se que o ensino não tem favorecido a perspectiva das inter-relações entre conhecimentos de Biologia e Química no EM. Graus de abstração requeridos para a compreensão de estruturas e fenômenos submicroscópicos poderiam ser atingidos se o ensino na área de CNT fosse desenvolvido de forma a favorecer necessárias conexões entre conceitos das disciplinas. Uma readequação dos programas de ensino favoreceria isso, com o estudo da energética celular no $3^{\circ}$ ano do EM, de forma articulada com a Química.

São inúmeras as possibilidades de produção de sentidos aos significados conceituais relativos a abordagens de diferentes contextos e temas em estudo. Contudo, é necessário levar em conta que "cada componente curricular tem sua razão de ser, seu objeto de estudo, seu sistema de conceitos e seus procedimentos metodológicos" (BRASIL, 2006, p. 102). Em Biologia são estudados os seres vivos e suas interações, em Química, os materiais, as substâncias, suas representações e transformações. Ambas têm em comum a investigação da natureza. O LDBEM ou o professor "compartilhando e articulando linguagens e modelos que compõem cada cultura científica, estabelece mediações capazes de produzir o conhecimento escolar, na inter-relação dinâmica de conhecimentos diversificados" (p. 103). As amplas interconexões conceituais se justificam na medida em que "cada disciplina tem razão de ser e não há maneira de se desenvolver capacidades tão abrangentes que se estendam para todas". (MALDANER e ZANON, 2010, pg. 350). Isso remete para dificuldades de compreensão conceitual decorrentes de representações 
inadequadas de objetos complexos como as interconversões ATP/ADP representadas nos LDBEM. Antes de incluir a imagem, o LDBEM apresenta de forma bem simplificada a equação da respiração aeróbia, dando o saldo de 36 ou de 38 ATPs.

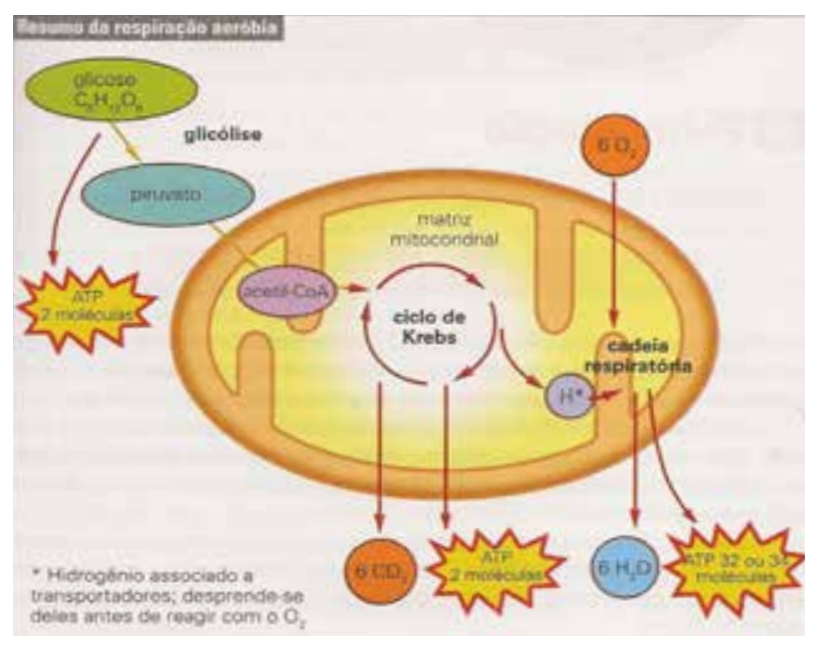

Figura 4: Esquema simplificado da respiração aeróbia (LDBEM1, p.203)

No LDBEM1, capítulo 9 denominado: Metabolismo energético da célula, consta no item Conceitos gerais: "os principais processos de liberação da energia contida nos alimentos orgânicos são: respiração aeróbia, respiração anaeróbia e fermentação" (p. 192, 2010). Diante desse enunciado, a Figura 4 pretende sintetizar o primeiro processo mencionado e aborda transformações em nível atômico-molecular, mediante as quais é produzida a 'energia' metabólica que possibilita a manutenção do processo vital, envolvendo em especial compreensões relativas às vias metabólicas mitocondriais.

Além das dificuldades na própria representação, ainda os termos utilizados podem ser relacionados com a categoria 1 , pois traz algumas das palavras-chave consideradas, ao mesmo tempo em que coloca o termo respiração ligado a outros conceitos, que podem constituir obstáculos epistemológicos, já que dificultam a articulação do conhecimento anterior dos estudantes com a nova realidade a ser estudada. Portanto, é concebida uma necessidade de organização do conhecimento de um nível macro para o micro, mas de forma categórica, desarticulada e fragmentada.

Abordagens reducionistas em LD de EM, limitadas a definições e abordagens de cunho formalístico e fragmentado, corroboram o entendimento de Cerri et al (2000, p. 128) de que "a forma e organização dos conteúdos não evidencia preocupação com a inter-relação funcional e mesmo estrututal e, portanto, o estudo se dá de forma linear e estanque". Conceitos carecem de ser melhor explicitados e interrelacionados. Resumidos a poucas linhas ou frases, introduzem muitos conceitos, meramente na forma de definição.

A imagem da representação da respiração aeróbia tem sua complexidade, pois sua compreensão requer o entendimento das transformações envolvidas no aproveitamento da energia de alimentos por meio da respiração celular. Conceitos básicos de Biologia e Química, abstratos por natureza, necessitam ser usados, com mobilização da capacidade de pensar conceitualmente sobre eles, entendendo-os de forma dinamicamente inter-relacionada. Será que o professor de Biologia do EM tem conhecimento de tal complexidade, ou repete as informações dos LD de forma a ser memorizada?

As compreensões, que extrapolam os conhecimentos usuais de um professor de Biologia, requerem conceitos químicos que, isolados e descontextualizados, não bastam por si só. Por exemplo, cabe ao professor de Química contribuir com as explicações relativas às substâncias, transformações e interações em nível atômico-molecular.

Nas imagens presentes nos LDBEM, observa-se grande quantidade de explicações, com pouca ou total ausência das fórmulas químicas dos processos abordados, apesar de as mesmas não garantirem nada sem significação. $A$ Figura 5 (extraída do LDBEM8, capítulo 11 denominado: Metabolismo Energético, no item 5. Respiração, sub-item 5. 2. Formação de acetil-CoA e ciclo de Krebs) é um exemplo dessa simplificação, que também se enquadra na categoria de análise 2: Energia nas substâncias, nas ligações químicas e nas reações dos organismos - ADP e ATP. O esquema de reações químicas apresentado, não evidencia que, até Piruvato, a glicólise produz ATP. Seria importante considerar as reações que produzem saldo energético de ATP. A "queima" de gordura na respiração produz mais 'energia' do que a de outras substâncias. Por exemplo: um grama de gordura na respiração produz duas vezes mais ATP do que um grama de carboidrato ou de proteína.

Há de se considerar ainda a falta de informações bioquímicas, fisiológicas e anatômicas sobre a decomposição do alimento para que possa ser absorvido a nível celular. As informações expressas na figura estão muito simplificadas, o que pode gerar incompreensões por parte dos estudantes. Além disso, introduz a nomenclatura das reações químicas sem utilizar a linguagem química adequada, gerando representações que sem a intervenção do professor constituem palavras vazias de significado. 


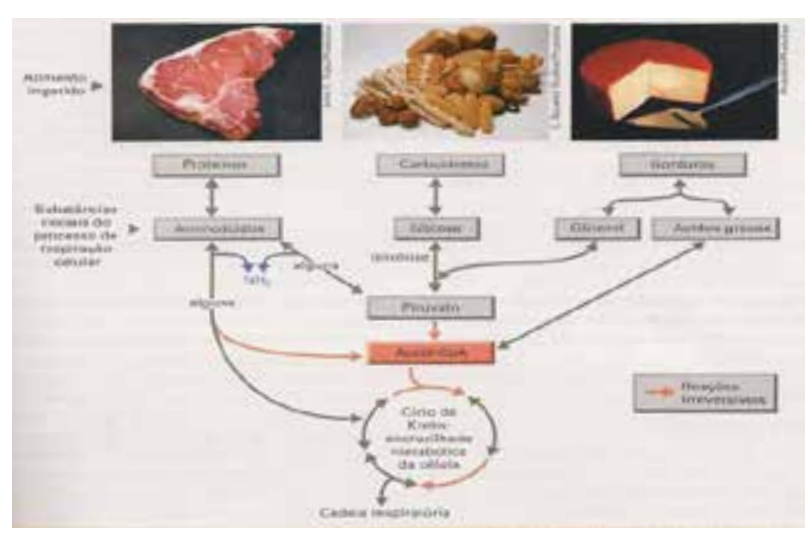

Figura 5: Alimentos e Ciclo de Krebs (LDBEM8, p.335)

Legenda da figura no LDBEM: A digestão dos carboidratos no sistema digestório produz vários tipos de monossacarídeos, dentre eles a glicose. Depois que ocorre a absorção, as células recebe esses monossacarídeos.

Diante da simplificação da imagem cabe refletir: como ocorrem as compreensões e significações conceituais, frente a estas limitações dos LD? Além disso, mais uma questão se coloca: ao ensinar a 'energia' relacionada ao metabolismo energético é obrigatória a inserção de explicações bioquímicas com o uso da linguagem adequada? Portanto, a presença de figuras sem fórmulas químicas dificultam aos estudantes constituirem um sentido do tema em estudo. Mesmo que o estudante consiga reproduzir a explicação do LD, é difícil dimensionar o sentido e o significado conceitual ao que está sendo explicado. Por isso defende-se a necessidade constante de interações entre as áreas de CNT, na perspectiva de um ensino e formação mais relevante, na área, além do comprometimento dos professores neste processo.

Pode-se afirmar que grande parte dos professores possivelmente ainda não percebeu a amplitude e a complexidade das relações envolvidas na compreensão escolar de energia. Limitações relativas a compreensões adequadas decorrem de uma formação sem interlocuções dentro da área de CNT, baseadas principalmente no uso dos LD, que possibilitam refletir que:

A abordagem dos conceitos diferencia-se apenas pela complexidade da explicação, isto é, fica mais na dependência do tipo de livro que, por exemplo, se este for volume único, os conceitos são pouco explicitados. Nestes termos, alguns livros se resumem a meras definições e assim, em poucas linhas ou frases são introduzidos muitos conceitos na forma de definição. [...] Ao nosso ver, a forma e organização dos conteúdos celulares apresentados pelos autores não evidencia preocupação com a inter-relação funcional e mesmo estrutural entre os diversos componentes celulares e, portanto, o estudo destes se dá de forma linear e estanque. (CERRI et al, 2000, p.128)

No contexto escolar, a inerente abstração nos processos de conhecimento sobre a 'energia' implica em inúmeras compreensões, (re)contextualizações e (re)significações. Por isso, o ensino não pode limitar-se a abordagens simplistas e precariamente relacionadas com situações reais, a exemplo de abordagens sobre as transformações físicas, químicas e biológicas que mantém a vida. Sua compreensão com (re)significação conceitual requer conhecimentos produzidos em contextos diversificados, os científicos e os cotidianos, os de nível teórico/abstrato e os vivenciais, a exemplo da respiração, que, na escola, saindo do plano da realidade vivida, é objeto de compreensão diferenciada, mediante relações no plano da idealidade dos conceitos.

Em algumas situações o conceito de energia, por ter um caráter mais abstrato, mas ao mesmo tempo ser identificado em várias formas, como luz e calor, passa a ser concebido como algo superior, não compreensível. Já, em outras, passa a ser considerado de forma simplista ignorando-se seu grau de abstração. As duas visões fazem parte da cultura primeira das pessoas, com forte apego ao imediatismo das evidências. Sabem que a energia é útil, identificam-na nos fenômenos elétricos. No entanto, não percebem outras possibilidades, além das diretamente observadas (AUTH, 2000, p.70).

Isso situa a importância de reflexões fundamentadas sobre a especificidade dos processos de significação dos conceitos escolares, levando em conta a noção de que os processos de conhecimento (científicos, escolares ou cotidianos), nunca lineares nem homogêneos, têm características descontinuístas e plurais (LOPES, 1999). Acreditamos que inter-relações de saberes por parte de professores e estudantes permitem um enriquecimento das ideias e argumentações, concebido como fator propulsor de mudanças no ensino de ciências, em contraposição a visões simplistas como a de que o professor seria o detentor de conhecimentos 'verdadeiros', bem como a concepção extremista de que o 'aluno constrói o seu conhecimento', o que não concebe o papel mediador do professor. Assim:

[...] o que afeta diretamente o desenvolvimento dos conteúdos científicos em sala de aula é a maneira como o docente é formado ou até mesmo a visão que possui sobre o que é Ciência e a atividade científica. [...] os professores parecem possuir uma concepção arraigada de que ensinar conteúdos científicos é transmitir conhecimentos prontos. Assim, [...] torna-se difícil esperar que 
um professor formado com uma concepção de Ciência como algo estático desenvolva práticas que privilegiem outra visão da atividade científica, se ele próprio não vivenciou tal processo. (LONGHINI, 2008, p. 243).

Dificuldades por parte dos professores em compreender e ensinar as interconversões ATP/ADP e os demais conteúdos relativos à 'energia' podem ser atribuídas a processos formativos baseados no currículo tradicional, em que cada disciplina trata os conteúdos sem interlocuções dos pares, não promovendo um ensino inter-relacional dentro da própria área. Limitações a compreensões conceituais, apesar de avanços nas abordagens, permanecem atreladas a abordagens inadequadas em LD. É necessário levar em conta que a compreensão dos objetos de estudo representados muitas vezes extrapola os conhecimentos usuais de um professor de Biologia; requer conceitos químicos que, isolados e descontextualizados, não bastam por si só.

Assim, a análise das figuras acena para a valorização de conhecimentos relativos aos processos de significação conceitual mediante ações coletivas com interação entre professores com formação disciplinar diversificada. Cabe ao professor de Química contribuir com explicações relativas às substâncias, transformações e interações em nível atômico-molecular. A atenção é direcionada a dificuldades na produção de sentidos aos significados dos conceitos científicos, na mobilização de relações dialéticas entre conhecimentos científicos e cotidianos que, sendo diferenciados, requerem-se mutuamente, em relação de reciprocidade.

Nesse contexto, sem nunca desconsiderar a importância do LD no contexto escolar, sugere-se que haja um olhar mais crítico sobre as formas como conteúdos/conceitos são abordados, na perspectiva de preservar a coerência com as ciências e, por outro lado, de valorizar as inter-relações necessárias a uma verdadeira compreensão conceitual. Nesse sentido:

[...] é preocupante evidenciar as dificuldades dos professores em conteúdos de Ciências, muitas vezes de nível elementar. Na carência de conhecimentos de conteúdos científicos, a interação acaba quase sempre sendo com o próprio livro didático disponível nas escolas, o que limita o aprofundamento de tais conteúdos. Além disso, a prática de consulta a livros didáticos pode reforçar alguns erros conceituais, devido à qualidade ainda sofrível de muitas destas obras. [...] Caso contrário, corremos o risco de continuarmos formando o professor pleno em metodologias, mas vazio em conteúdos. (LONGHINI, 2008, p.251).

Cabe reafirmar que o ensino sobre a energética celular exige, por parte dos professores de Biologia, abertura para interagir com os professores de Química, e vice-versa, com ações articuladas que permitam compreensões coerentes com as ciências. Para avançar na significação dos conceitos, é necessário mobilizar pensamentos em redes de relações entre conceitos, sendo imprescindível a ajuda dos professores das demais disciplinas da área. Por exemplo, o professor de Química poderá contribuir com explicações relativas às partículas e interações em nível atômico-molecular.

E, sem a compreensão de um ensino de ciências articulado com as especificidades das disciplinas, bem como sem considerar os processos de desenvolvimento mental dos estudantes, necessários às compreensões de conceitos complexos, o ensino da área permanecerá distante da finalidade de desenvolver o pleno desenvolvimento dos educandos (BRASIL, 1996).

Tudo isso referenda a visão do papel essencial da escola: o de propiciar o acesso pedagógico aos conhecimentos científicos de modo que o estudante, tendo se apropriado das linguagens e das formas de pensamento próprias às ciências, saiba fazer uso delas frente a situações-problema em situações reais em estudo.

\section{Conclusão}

Resultados do trabalho apontam para a necessidade de compreender limitações de abordagens conceituais de energia em LDBEM utilizados no EM. Não desconsiderando a importância do LD no contexto escolar, sugere-se que haja um olhar mais crítico sobre as formas como conteúdos/conceitos estruturantes do conhecimento na ciência são abordados, na perspectiva de preservar a coerência com o conhecimento científico. Por outro lado, valorizar as inter-relações necessárias a compreensão conceitual, enquanto sistemas de relações a serem considerados no ensino de temas complexos, como é o caso de 'energia'. Nessa perspectiva, cabe aos cursos de formação de professores, inicial ou continuado, abrir espaços para discussões sobre fatores que limitam as práticas docentes, cerceadas ao seguimento de um LD ou a concepções ultrapassadas, sem estabelecimento de relações dentro e fora da área do conhecimento.

Há a necessidade de uma maior conscientização sobre limitações de determinadas abordagens. Ainda, considerar que o professor não tome o LD como único orientador na apresentação dos conteúdos/conceitos. Assim, é necessário considerar a problemática que diz respeito aos crescentes graus de complexidade que acompanham o ensino desses conteúdos. Abordagens dos mesmos têm se mostrado inadequadas por não permitirem compreensões conceituais efetivamente transformadoras dos 
conhecimentos dos estudantes. Quando uma abordagem não desafia o pensamento para aprender os necessários processos de inter-relação conceitual, ela limita, distorce ou compromete a aprendizagem, em prejuízo ao entendimento conceitual e a potencialização dos processos de desenvolvimento sociocognitivo dos educandos.

Melhorias no ensino de CNT precisam contemplar os LD, mas não apenas os mesmos, sendo importante usar uma multiplicidade de fontes de informação, como por exemplo, artigos científicos, sites, pesquisas e interlocuções na própria área, dentre outros recursos didáticos, possibilitando o desenvolvimento de um ensino em CNT dinâmico e enriquecedor, coerentemente com as OCNEM (BRASIL, 2006).

A complexidade na expressão conceitual, vinculada a um grau de abstração elevado, constitui-se outra dificuldade, que pode ser verificada nos descritores e nas imagens. Ao reconhecer este conjunto de descritores, abre-se uma perspectiva de reflexão sobre a organização do currículo escolar ainda alinhado ao proposto pelos LD. E, principalmente, no que se refere ao processo de formação docente em que os sujeitos percebam o seu papel no ensino e na significação conceitual.

\section{CORPUS - CONJUNTO DE DOCUMENTOS UTILIZADOS E ANALISADOS NA PESQUISA}

BIZZO, N. Novas Bases da Biologia - das moléculas às populações. Volume único. São Paulo: Editora Ática, 2010, 400 pg.

GEWANDSNAJDER, F.; LINHARES, S. de V. Biologia Hoje. Vol. 1. Editora Ática: 2010

LOPES, Sônia. Biologia. Volume 1. Org.: Sônia Lopes; Sergio Rosso - 2 ed. São Paulo: Saraiva, 2010.

MARTHO, G. R.; AMABIS, J. M. Biologia: Biologia das células. Volume 1. São Paulo: Editora Moderna, 2010.

MENDONÇA, V.; LAURENCE, J. Biologia para nova Geração. Vol. 1. Editora Nova Geração: 2010

PEZZI; A. P.; GOWDAK, O.G.; e MATTOS, N. S. de. Biologia. Volume 1: Citologia; Embriologia e Histologia- Ensino Médio. $1^{\text {a }}$ edição - Editora FTD: São Paulo, 2010 - 192p.

SANTOS, F. S. dos; AGUILAR, J. B.V.; OLIVEIRA, M. M. A. de. et al. Ser Protagonista. Biologia $1^{\circ}$ ano - Ensino Médio - 368 p. Rio de Janeiro: Edições SM, 2010.

SILVA JUNIOR, C. da. Biologia: volume 1/ Org.: César da Silva Júnior; Sezar Sasson; Nelson Caldini Júnior . 9. ed. São Paulo: Saraiva, 2011

SILVA JUNIOR, C. da. Biologia: volume 3/ Org.: César da Silva Júnior; Sezar Sasson; Nelson Caldini Júnior . 9. ed. São Paulo: Saraiva, 2011

\section{REFERÊNCIAS BIBLIOGRÁFICAS}

AMARAL, I. A.; MEGID NETO, J. Os fundamentos do ensino de Ciências e o livro didático. In: O livro didático de ciências no Brasil. FRACALANZA, Hilário; MEGID NETO, Jorge (orgs.). Campinas: Komedi, 2006.

ANGOTTI, J. A. P. Fragmentos e Totalidades no Conhecimento Científico e no Ensino de Ciências. 1991. Tese de doutorado. Universidade de São Paulo - USP. São Paulo (SP).

AUTH, M. A. Conceitos Unificadores e o Ensino de Ciências. In: Espaços da Escola, ljuí/RS, v. 38, p. 63-80, 2000.

BARROS, H. L. de C. Processos Endotérmicos e Exotérmicos: Uma Visão Atômico- Molecular. In: Química Nova na Escola. v. 31 n. 4, Nov. 2009.

BRASIL. Ministério da Educação, Secretaria de Educação Média e Tecnológica. Lei de Diretrizes e Bases da Educação Nacional. Brasília: Ministério da Educação, 1996.

Ministério da Educação - MEC, Secretaria de Educação Básica. OrientaçõesCurriculares Nacionais para o Ensino Médio: Ciências da natureza, matemática e suas tecnologias. Brasília: 2006. 135 p.

. Ministério da Educação - MEC, Secretaria de Educação Básica. Guia de livros didáticos : PNLD 2012 : Biologia. Brasília: 2011. 76 p.

CARVALHO, Graça Simões; FREITAS, Maria Luísa; PALHARES, Pedro e AZEVEdo, Fernando. Investigação em Didáctica da Biologia no $1^{\circ}$ Ciclo do Ensino Básico, In Saberes e Práticas na Formação de Professores e Educadores. In: Actas das Jornadas DCILM 2002. Braga: Departamento de Ciências Integradas e Língua Materna da Universidade do Minho (eds.). 2003.

CERRI, Y.L. et al. Livros Didáticos, Analogias e Mapas Conceituais no Ensino de Célula. In: ARAGÃO, Rosália M. R. de; CERRI, Yara L. N.S.; SCHNETZLER, Roseli P. (Orgs).Modelos de ensino: corpo humano, célula, reações de combustão. Piracicaba: UNIMEP/CAPES/ PROIN, 2000. 235 p.

EMMEL, R.; GULLICH, Roque I; PANSERA-DE-ARAúJO, M.C. Interfaces da pesquisa sobre o livro didático de Ciências. In: VII Encontro Nacional de Pesquisa em Educação nas Ciências. Florianópolis: ABRAPEC, 2009.

. "Estado da Arte" e Coletivos de Pensamento da Pesquisa sobre o Livro Didático no Brasil. 2011. Dissertação de Mestrado. Universidade Regional do Noroeste do Estado do Rio Grande do Sul. Ijuí. 
FRACALANZA, Hilário. O que sabemos sobre os livros didáticos para o ensino de Ciências no Brasil. 1993. Tese (Doutorado) - Faculdade de Educação, UNICAMP, Campinas, 1993.

GÜLLICH, Roque Ismael da Costa. Desconstruindo a imagem do livro didático no ensino de ciências. In: Revista SETREM. Três de Maio, v. 4, n. 3, p. 43 - 51, jan. 2004.

O livro didático, o professor e o ensino

de ciências: um processo de investigação-formação-ação. Tese de Doutorado. Universidade Regional do Noroeste do Estado do Rio Grande do Sul. ljuí: 2012.

KRASILCHIK, M. Reformas e realidade: o caso do ensino das ciências. In: São Paulo em Perspectiva, v. 14 n.1, p.85-93, 2000.

LONGHINI, M. D. O Conhecimento do Conteúdo Científico e a Formação do Professor das Séries Iniciais do Ensino Fundamental. In: Investigações em Ensino de Ciências - v. 13(2), p.241-253, 2008

LOPES, A. C. Bachelard: O Filósofo da Desilusão. In: Caderno Catarinense de Ensino de Física. v. 13, n. 3 : p. 248-273, dez.1996.

Conhecimento Escolar: Ciência e Cotidiano. Rio de Janeiro: Ed. UERJ, 1999.

. Currículo e epistemologia. Ijuí: Unijuí, 2007.

LÜDKE, M. e ANDRÉ, M. E. D. A. Pesquisa em educação: abordagens qualitativas. São Paulo: EPU, 1986.

MARQUES, M. O. Conhecimento e Educação. Ijuí: Ed. UNIJUÍ, 1988.

MARTINS, Isabel. Analisando Livros Didáticos na perspectiva dos Estudos do Discurso: compartilhando reflexões e sugerindo uma agenda para a pesquisa. Revista Pro-Posições. Campinas. v. 17, n. 1 (49) - jan./ abr. 2006.

MEGID NETO, Jorge; FRACALANZA, Hilário. O livro didático de Ciências problemas e soluções. In: O livro didático de ciências no Brasil. FRACALANZA, Hilário; MEGID NETO, Jorge (orgs.). Campinas: Komedi, 2006.

MORAES, R.; GALIAZZI, M. C. Análise Textual Discursiva. ljuí: Unijuí, 2007.

MORTIMER, Eduardo F. A evolução dos livros didáticos de Química destinados ao ensino secundário. Em Aberto, Brasília, v.7, n.40, p. 24-41, out. 1988.

. AMARAL, L. O. F. Quanto mais quente melhor. In: Química Nova na Escola. São Paulo: Divisão de Ensino de Química da Sociedade Brasileira de Química. N.7, Maio 1998, p. 30-34.

OCCELLI, M.; VALEIRAS, N. Los Libros de Texto de Ciencias como Objeto de Investigación: Uma Revisión Bibliográfica. In: Ensenãnza De Las Ciencias. Barcelona: Revista de investigación y experiências didácticas. Núm.31.2, 2013, p.133-152.

OLIVEIRA, J. R. de; SANTOS, J. M. A energia e química. In: Química Nova na Escola. São Paulo: Divisão de Ensino de Química da Sociedade Brasileira de Química. N.8, Novembro 1998, p.19-22.

PANSERA DE ARAÚJO M. C.; NONENMACHER, S. Energia: Um Conceito Presente nos Livros Didáticos de Física, Biologia e Química do Ensino Médio. In: Poiésis, Tubarão, v. 2, n. 1, p. 1 - 13, Jan./Jun. 2009.

PIMENTEL, Jorge R. Livros didáticos de Ciências: a Física e alguns problemas. Caderno Catarinense de Ensino de Física, Florianópolis, v.15, n.3, p. 308-318, dez. 1998.

PRETTO, Nelson de Luca. A ciência nos livros didáticos. Campinas-SP: Ed. Da UNICAMP; Salvador: CED/ UFBA, 1985. 95 p.

SELLES, Sandra Escovedo; FERREIRA, Márcia Serra. Influências histórico-culturais nas representações sobre as estações do ano em livros didáticos de ciências. In: Ciência \& Educação, Bauru, v. 10, n. 1, p. 101-110, 2004.

SILVA, Rafael Moreira. Textos didáticos: crítica e expectativa. São Paulo: Alínea. 2000.

VIGOTSKI, Lev. S. A construção do pensamento e da linguagem. Tradução de Paulo Bezerra. São Paulo: Martins Fontes, 2001.

WIRZBICKI, S. M.; ZANON, L. B. A Complexidade de Processos de Significação Conceitual de Energia num Espaço de Formação para o Ensino de Ciências. In: VII ENPEC - Encontro Nacional de Pesquisa em Educação em Ciências. Florianópolis. Anais do VII ENPEC - Encontro Nacional de Pesquisa em Educação nas Ciências. Florianópolis: ABRAPEC, 2009.

Abordagens e reflexões sobre a significação conceitual de energia em espaços interativos de formação de professores. 2010. Dissertação de Mestrado. Universidade Regional do Noroeste do Estado do Rio Grande do Sul. Ijuí. 